\title{
Secondary hypertension in adults
}

Troy Hai Kiat $\underline{\text { Puar }}^{1}$, MBBS, MRCP, Yingjuan Mok $^{2}$, MBBS, MRCP, Roy Debajyoti ${ }^{3}$, MD, FRCP, Joan Khoo ${ }^{1}$, MBBS, MRCP, Choon How $\underline{H o w}^{4}$, MMed, FCFP, Alvin Kok Heong $\underline{\mathrm{Ng}}^{3}$, MBChB, FRACP

Mr Ali, aged 55 years, visited you for a scheduled follow-up for his hypertension, Type 2 diabetes mellitus, ischaemic heart disease and a prior ischaemic stroke. Your first consultation with him was two weeks ago, when he transferred his medical follow-up to your clinic. You reviewed his medications and noted that he is currently taking five antihypertensive medications (hydrochlorothiazide, hydralazine, enalapril, atenolol and amlodipine). His blood pressure during the visit was $154 / 96 \mathrm{mmHg}$, while his blood pressure recorded at home was generally about $150 / 90 \mathrm{mmHg}$ or higher. You reviewed his first set of blood investigations at your clinic and noted that he has hypokalaemia (serum potassium $3.0 \mathrm{mmol} / \mathrm{L}$ ).

\section{WHAT IS SECONDARY HYPERTENSION?}

Hypertension is the single biggest contributor to the global burden of disease, ${ }^{(1)}$ and is the most common chronic medical condition presenting to primary care physicians in Singapore. ${ }^{(2}$ While the majority of patients have essential hypertension that does not have an identifiable cause, it is important to recognise secondary causes of hypertension (Table I), as they may be curable. Left undiagnosed, secondary hypertension can lead to resistant hypertension, cardiovascular and renal complications, multiple specialist referrals and an unnecessary burden on the healthcare system.

\section{HOW COMMON IS THIS IN MY PRACTICE?}

About $10 \%$ of patients with hypertension have a secondary cause. Clinicians often consider secondary causes such as renal disease or coarctation of the aorta in children and young adults aged below 30 years. However, it is important to realise that secondary causes are also common in older patients, particularly primary aldosteronism, renal disease and obstructive sleep apnoea (OSA). The prevalence of these conditions is even higher in patients with resistant hypertension, defined as blood pressure (BP) $\geq 140 / 90 \mathrm{mmHg}$ despite the use of three antihypertensive medications, including a diuretic. ${ }^{(3-6)}$ Other causes, such as pheochromocytoma, are less common but equally important to recognise, as failure to diagnose and treat them can lead to catastrophic consequences. ${ }^{(7)}$

\section{WHAT CAN I DO IN MY PRACTICE?}

The diagnosis of hypertension should be confirmed with at least two BP readings ( $\geq 140 / 90 \mathrm{mmHg}$ ) using a mercury sphygmomanometer or another noninvasive device at two separate settings. Following this, a directed history and physical examination should be performed to consider secondary causes of hypertension; this should always include an evaluation for other cardiovascular risk factors, including diabetes mellitus, hyperlipidaemia, family history and smoking status.

Important clues suggesting an underlying secondary cause are (a) young patient $<30$ years of age (renal causes or coarctation of the aorta); (b) symptoms or signs suggesting secondary causes (Table I); (c) indication of severe (BP $\geq 180 / 110 \mathrm{mmHg}$ ) or resistant hypertension ( $\mathrm{BP} \geq 140 / 90 \mathrm{mmHg}$ despite concurrent use of three antihypertensive medications from different classes, including a diuretic); and (d) acute worsening of hypertension in a patient with previously stable control.

\section{Primary aldosteronism}

First described by Jerome Conn in 1950, primary aldosteronism (PA) was thought to be rare $(<1 \%)$ and that hypokalaemia was a sine qua non. ${ }^{(8)}$ However, more sensitive laboratory assays and the use of the aldosterone-to-renin ratio (ARR) as a screening test has led to an increase in diagnosis of PA worldwide. ${ }^{(9)}$ It is currently well-recognised that only a minority of patients $(\sim 30 \%)$ have hypokalaemia. ${ }^{(5)}$ One local polyclinic study screened and confirmed PA in 5\% of hypertensive patients, ${ }^{(4)}$ while another study at a local tertiary centre found a prevalence of $13 \%$ in diabetic patients with resistant hypertension. ${ }^{(3)}$ It is important to diagnose these patients, as they often have increased cardiovascular morbidity and mortality than age-, sex- and BP-matched patients with essential hypertension, ${ }^{(10)}$ and treatment can lead to reversal of end-organ damage. ${ }^{(11-14)}$ Surgery is usually recommended for patients with a unilateral adrenal adenoma (termed Conn's syndrome), while patients who have bilateral adrenal hyperplasia or who are not suitable for or keen on surgery are treated with mineralocorticoid receptor antagonists (spironolactone or eplerenone). Surgery

${ }^{1}$ Department of Endocrinology, ${ }^{2}$ Department of Respiratory and Critical Care Medicine, ${ }^{3}$ Department of Renal Medicine, ${ }^{4}$ Care and Health Integration, Changi General Hospital, Singapore

Correspondence: Dr Troy Hai Kiat Puar, Consultant, Department of Endocrinology, Changi General Hospital, 2 Simei Street 3, Singapore 529889. troy_puar@cgh.com.sg 
Table I. Causes of secondary hypertension and suggestive findings.

\begin{tabular}{|c|c|c|}
\hline Condition & Symptom/sign & Investigation \\
\hline $\begin{array}{l}\text { Renal artery } \\
\text { stenosis }\end{array}$ & $\begin{array}{l}\text { - Renal bruit } \\
\text { - Worsening in serum creatinine level }>30 \% \text { after use of } \\
\text { angiotensin-converting enzyme inhibitor or angiotensin II } \\
\text { receptor blocker }\end{array}$ & $\begin{array}{l}\text { - Ultrasonography (US) of the kidneys } \\
\text { (one kidney smaller by }>1.5 \mathrm{~cm} \\
\text { compared with contralateral) } \\
\text { - Duplex Doppler US of renal arteries } \\
\text { - Magnetic resonance/computed } \\
\text { tomographic renal angiography } \\
\text { - Percutaneous renal arteriogram }\end{array}$ \\
\hline $\begin{array}{l}\text { Renal parenchymal } \\
\text { disease }\end{array}$ & Mostly asymptomatic & $\begin{array}{l}\text { - Serum creatinine test (elevated level) } \\
\text { - Urinalysis }\end{array}$ \\
\hline $\begin{array}{l}\text { Primary } \\
\text { aldosteronism }\end{array}$ & Mostly asymptomatic & $\begin{array}{l}\text { - Aldosterone and renin levels (with ratio) } \\
\text { - Hypokalaemia (in a minority) }\end{array}$ \\
\hline Pheochromocytoma & $\begin{array}{l}\text { - Episodic headaches, sweating, palpitations and flushing } \\
\text { - Labile blood pressure (BP)/hypertensive } \\
\text { episodes precipitated by drugs: D2-antagonists } \\
\text { (e.g. metoclopramide), beta-blockers, sympathomimetics, } \\
\text { opioids, tricyclic antidepressants }\end{array}$ & 24-hr urinary fractionated metanephrines \\
\hline Cushing's syndrome & $\begin{array}{l}\text { - Moon facies, central obesity, thin skin, easy bruising } \\
\text { - Exogenous steroid use }\end{array}$ & 24-hr urinary free cortisol \\
\hline $\begin{array}{l}\text { Hypothyroidism/ } \\
\text { hyperthyroidism }\end{array}$ & $\begin{array}{l}\text { - Symptoms of hypothyroidism or hyperthyroidism } \\
\text { (e.g. gain/loss of weight, cold/heat intolerance) }\end{array}$ & Thyroid function tests \\
\hline $\begin{array}{l}\text { Coarctation of the } \\
\text { aorta }\end{array}$ & $\begin{array}{l}\text { - Radio-femoral delay } \\
\text { - Differential BP in arms and legs (systolic BP > } 20 \text { mmHg) }\end{array}$ & $\begin{array}{l}\text { Transthoracic echocardiogram } \\
\text { (less accurate in adults) }\end{array}$ \\
\hline $\begin{array}{l}\text { Obstructive sleep } \\
\text { apnoea }\end{array}$ & $\begin{array}{l}\text { - Obesity } \\
\text { - Daytime somnolence, fatigue }\end{array}$ & Polysomnography \\
\hline Medication & $\begin{array}{l}\text { - Oral contraceptives, nonsteroidal anti-inflammatory drugs } \\
\text { - Steroids, sympathomimetic drugs (decongestants, diet pills) } \\
\text { - Illicit drugs (cocaine, amphetamines, } \\
\text { Ecstasy/3,4-methylenedioxymethamphetamine)(15) }\end{array}$ & - \\
\hline
\end{tabular}

improves BP in all patients, and hypertension is cured in about $50 \%$ of patients. ${ }^{(5)}$

Patients with PA are often aged about 50-70 years; only a minority have hypokalaemia and almost all are asymptomatic. ${ }^{(3,4,9)}$ Hence, it is important to consider screening patients for this condition. The Endocrine Society in the United States released a guideline ${ }^{(5)}$ in March 2016 recommending broadened indications for screening of PA in patients with hypertension (Table II).

The most important conditions prior to testing are that hypokalaemia is corrected and spironolactone is stopped for at least six weeks. While antihypertensive medications should also be stopped prior to tests (as many affect aldosterone, renin levels and ARR), ${ }^{(16-18)}$ this can be difficult and possibly dangerous. ${ }^{(19)}$ Several medications (e.g. verapamil, hydralazine and prazosin/ doxazosin) have minimal effects on ARR and are preferred. If their use is not feasible, we recommend screening patients while keeping them on their current medications, ${ }^{(3-5)}$ and referral to an endocrinologist if the test is positive. The Endocrine Society observed that the current greatest problem is that the screening test is often not performed, leading to an underdiagnosis of this condition. ${ }^{(5)}$

\section{Renal artery stenosis and renal parenchymal disease}

Hypertension due to renal causes can be categorised as resulting from renovascular causes and renal parenchymal disease. Renovascular causes include renal artery stenosis
Table II. Screening for primary aldosteronism (adapted from the Endocrine Society Guidelines 2016).(5)

\section{Consider testing in patients with:}

1. Repeat blood pressure (BP) levels $>150 / 100 \mathrm{mmHg}$

2. Resistant hypertension ( $B P \geq 140 / 100 \mathrm{mmHg}$ while on three antihypertensive medications, including diuretics)

3. Controlled hypertension (BP $<140 / 100 \mathrm{mmHg}$ ) on $\geq 4$ antihypertensive medications

4. Hypertension associated with hypokalaemia (spontaneous or diuretic-induced)

\section{Prior to test:}

1. Stop spironolactone/eplerenone/amiloride for at least six wk

2. Correct potassium to within normal range Test:

Aldosterone, renin and potassium, performed at 8-10 am (seated)

Test is positive if both conditions are met:

$$
\text { 1. } \frac{\text { Aldosterone }(\mathrm{pmol} / \mathrm{L})}{\text { Renin }(\mathrm{mcg} / \mathrm{L} / \mathrm{hr})}(\mathrm{ARR})^{*}>550 \text { and }
$$$$
\text { 2. } \text { Aldosterone }^{+}>416 \mathrm{pmol} / \mathrm{L}
$$

*Aldosterone measured as plasma aldosterone concentration, renin measured as plasma renin activity. tPlasma aldosterone concentration often reported in $\mathrm{pmol} / \mathrm{L}$. To convert to $\mathrm{ng} / \mathrm{dL}$, divide by 27.7 , e.g., aldosterone $416 \mathrm{pmol} / \mathrm{L}=15 \mathrm{ng} / \mathrm{dL}$. In $\mathrm{ng} / \mathrm{dL}$, ARR $>20$ is the condition for a positive test (i.e. $550 \div 27.7=20$ ). ARR: aldosterone-to-renin ratio

(RAS) due to atherosclerotic disease or fibromuscular dysplasia (FMD), arteritis or extrinsic compression of a renal artery. Renal parenchymal disease includes acute and chronic glomerular 
diseases, chronic tubulointerstitial disease, polycystic kidney disease, diabetic nephropathy and obstructive uropathy. Based on these aetiologies, the baseline investigations for renovascular causes are serum creatinine test, urinalysis and ultrasonography of the kidneys. Further investigations for renal parenchymal disease are generally based on a nephrologist's assessment.

Clinical situations that alert a physician to RAS are $>30 \%$ rise in serum creatinine level after initiation of an angiotensinconverting enzyme (ACE) inhibitor or angiotensin II receptor blocker (ARB), discrepancy in kidney sizes of more than $1.5 \mathrm{~cm}$ or recurrent flash pulmonary oedema in a patient with normal left ventricular ejection fraction. The first-line investigation for suspicion of RAS is duplex Doppler ultrasonography of the renal arteries. ${ }^{(20)}$ This is an effective screening test when performed by an experienced vascular radiographer. Magnetic resonance or computed tomographic angiography may be required to confirm the anatomic diagnosis. If there is a high suspicion of RAS requiring intervention, however, the gold standard is renal artery angiography. ${ }^{(21)}$

Treatment involves correction of modifiable cardiovascular risk factors and control of hypertension. Indications for percutaneous intervention are FMD, short duration of BP elevation prior to diagnosis of RAS and recurrent flash pulmonary oedema. As for atherosclerotic RAS, the first-line treatment is optimal medical therapy to achieve BP targets; if this fails, percutaneous renal revascularisation is indicated. ${ }^{(22)}$

\section{Obstructive sleep apnoea}

OSA is a sleep-related breathing disorder characterised by episodes of complete or partial upper airway obstruction occurring during sleep, resulting in repetitive oxygen desaturation and sleep fragmentation. Typical symptoms associated with OSA include excessive daytime sleepiness, nocturnal gasping or choking events, snoring and unrefreshing sleep. A sleep study (polysomnography) is required for the diagnosis of OSA.

OSA is common, with a recent study placing the estimated prevalence of moderate to severe OSA at 30.5\% in Singapore's population. ${ }^{(23)}$ Male gender, obesity and middle age have been identified as associated risk factors. ${ }^{(24)}$ OSA has been strongly associated with hypertension in large cross-sectional and longitudinal studies. ${ }^{(25-27)}$ One study showed that OSA was prevalent in $95 \%$ of men and $65 \%$ of women with drug-resistant hypertension. ${ }^{(28)}$

Continuous positive airway pressure (CPAP) is the standard treatment for OSA patients; its primary benefits are the improvement of daytime sleepiness and quality of life. ${ }^{(29)}$ Although CPAP treatment only appears to lower BP by a small margin $(\sim 2 \mathrm{mmHg})$, ${ }^{(30)}$ even a reduction of 1-5 $\mathrm{mmHg}$ has been shown to reduce cardiovascular risks significantly. ${ }^{(31)}$ In a recent study, CPAP was able to further decrease the 24-hour mean and diastolic BP in OSA patients with drug-resistant hypertension who were taking an average of 3.8 antihypertensive medications. ${ }^{(32)}$ The magnitude of $\mathrm{BP}$ reduction with CPAP is far less than that achieved with antihypertensive medications ${ }^{(33)}$ and these patients should continue to be managed with dietary and lifestyle modifications as well as optimal pharmacotherapy.

Since many patients with OSA remain undiagnosed, a high index of clinical suspicion is needed, particularly in patients with drug-resistant hypertension. The presence of typical symptoms of OSA, such as loud snoring, witnessed apnoea and daytime somnolence, or known risk factors for OSA, should prompt the physician to consider referral to a sleep specialist.

\section{WHEN SHOULD I REFER TO A SPECIALIST?}

Referral should be considered when a secondary cause of hypertension is suspected, and the choice of specialist should be based on the likely underlying cause. Other factors that should prompt a referral are young hypertensive patients $(<30$ years of age); a positive aldosterone-to-renin ratio with elevated aldosterone level (Table II); and $>30 \%$ rise in serum creatinine level after initiation of an ACE inhibitor or ARB, or discrepant kidney size.

After prescribing oral potassium supplements to correct Mr Ali's hypokalaemia, you proceeded to check his aldosterone and renin levels, which were $1,186 \mathrm{pmol} / \mathrm{L}$ and $0.15 \mathrm{mcg} / \mathrm{L} / \mathrm{hr}$, respectively, with an aldosterone-to-renin ratio of 7,907 (> 550). As this was a positive screening test for primary aldosteronism, you referred him to an endocrinologist. Further tests confirmed the diagnosis of a unilateral adrenal adenoma causing primary aldosteronism. After adrenalectomy, his hypokalaemia resolved, while his hypertension improved to a blood pressure of $124 / 82 \mathrm{mmHg}$ on only two antihypertensive medications, atenolol and nifedipine.

\section{TAKE HOME MESSAGES}

1. Secondary hypertension is a common cause of hypertension in adults, occurring in about $10 \%$ of hypertensive patients.

2. Failure to recognise secondary causes can lead to resistant hypertension, cardiovascular complications or complications of the underlying condition.

3. In younger adults ( $<30$ years of age), renal causes such as glomerulonephritis and coarctation of the aorta should be considered.

4. In older adults, primary aldosteronism, RAS and OSA are common and often underdiagnosed. Screening tests, if available, should be performed to detect these conditions.

5. Diagnosis and treatment of causes of secondary hypertension can lead to good clinical outcomes. 
ABSTRACT Secondary hypertension occurs in a significant proportion of adult patients ( $10 \%)$. In young patients, renal causes (glomerulonephritis) and coarctation of the aorta should be considered. In older patients, primary aldosteronism, obstructive sleep apnoea and renal artery stenosis are more prevalent than previously thought. Primary aldosteronism can be screened by taking morning aldosterone and renin levels, and should be considered in patients with severe, resistant or hypokalaemia-associated hypertension. Symptoms of obstructive sleep apnoea should be sought. Worsening of renal function after starting an angiotensin-converting enzyme inhibitor suggests the possibility of renal artery stenosis. Recognition, diagnosis and treatment of secondary causes of hypertension lead to good clinical outcomes and the possible reversal of end-organ damage, in addition to blood pressure control. As most patients with hypertension are managed at the primary care level, it is important for primary care physicians to recognise these conditions and refer patients appropriately.

Keywords: primary aldosteronism, obstructive sleep apnea, renal artery stenosis, secondary hypertension

\section{REFERENCES}

1. Poulter NR, Prabhakaran D, Caulfield M. Hypertension. Lancet 2015; 386:801-12.

2. Ministry of Health, Singapore. Primary Care Survey 2010 [online] Available at: https:/www.moh.gov.sg/content/dam/moh_web/Publications/ Reports/2014/Primary\%20Care\%20Survey\%202010\%20report.pdf. Accessed April 25, 2016.

3. Mukherjee JJ, Khoo CM, Thai AC, et al. Type 2 diabetic patients with resistant hypertension should be screened for primary aldosteronism. Diab Vasc Dis Res 2010; 7:6-13.

4. Loh KC, Koay ES, Khaw MC, Emmanuel SC, Young WF Jr. Prevalence of primary aldosteronism among Asian hypertensive patients in Singapore. J Clin Endocrinol Metab 2000; 85:2854-9.

5. Funder JW, Carey RM, Mantero F, et al. The Management of Primary Aldosteronism: Case Detection, Diagnosis, and Treatment: An Endocrine Society Clinical Practice Guideline. J Clin Endocrinol Metab 2016; jc20154061.

6. Pedrosa RP, Drager LF, Gonzaga CC, et al. Obstructive sleep apnea: the most common secondary cause of hypertension associated with resistant hypertension. Hypertension 2011; 58:811-7.

7. Lo CY, Lam KY, Wat MS, Lam KS. Adrenal pheochromocytoma remains a frequently overlooked diagnosis. Am J Surg 2000; 179:212-5.

8. CONN JW. Primary aldosteronism. J Lab Clin Med 1955; 45:661-4.

9. Mulatero P, Stowasser M, Loh KC, et al. Increased diagnosis of primary aldosteronism, including surgically correctable forms, in centers from five continents. J Clin Endocrinol Metab 2004; 89:1045-50.

10. Milliez P, Girerd X, Plouin PF, et al. Evidence for an increased rate of cardiovascular events in patients with primary aldosteronism. J Am Coll Cardiol 2005; 45:1243-8.

11. Catena C, Colussi G, Lapenna R, et al. Long-term cardiac effects of adrenalectomy or mineralocorticoid antagonists in patients with primary aldosteronism. Hypertension 2007; 50:911-8.

12. Rossi GP, Sacchetto A, Visentin P, et al. Changes in left ventricular anatomy and function in hypertension and primary aldosteronism. Hypertension 1996; 27:1039-45.

13. Fourkiotis V, Vonend O, Diederich S, et al; Mephisto Study Group.
Effectiveness of eplerenone or spironolactone treatment in preserving renal function in primary aldosteronism. Eur J Endocrinol 2012; 168:75-81.

14. Ahmed AH, Gordon RD, Sukor N, Pimenta E, Stowasser M. Quality of life in patients with bilateral primary aldosteronism before and during treatment with spironolactone and/or amiloride, including a comparison with our previously published results in those with unilateral disease treated surgically. J Clin Endocrinol Metab 2011; 96:2904-11.

15. Ferdinand KC. Substance Abuse and Hypertension. J Clin Hypertens (Greenwich) 2000; 2:37-40.

16. Ahmed AH, Gordon RD, Taylor $\mathrm{P}$, et al. Effect of atenolol on aldosterone/ renin ratio calculated by both plasma Renin activity and direct Renin concentration in healthy male volunteers. J Clin Endocrinol Metab 2010; 95:3201-6.

17. Calhoun DA, Nishizaka MK, Zaman MA, Thakkar RB, Weissmann P. Hyperaldosteronism among black and white subjects with resistant hypertension. Hypertension 2002; 40:892-6.

18. Gallay BJ, Ahmad S, Xu L, Toivola B, Davidson RC. Screening for primary aldosteronism without discontinuing hypertensive medications: plasma aldosterone-renin ratio. Am J Kidney Dis 2001; 37:699-705.

19. Fischer E, Beuschlein F, Bidlingmaier M, Reincke M. Commentary on the Endocrine Society Practice Guidelines: Consequences of adjustment of antihypertensive medication in screening of primary aldosteronism. Rev Endocr Metab Disord 2011; 12:43-8.

20. Williams GJ, Macaskill P, Chan SF, et al. Comparative accuracy of renal duplex sonographic parameters in the diagnosis of renal artery stenosis: paired and unpaired analysis. AJR Am J Roentgenol 2007; 188:798-811.

21. Vasbinder GB, Nelemans PJ, Kessels AG, et al; Renal Artery Diagnostic Imaging Study in Hypertension (RADISH) Study Group. Accuracy of computed tomographic angiography and magnetic resonance angiography for diagnosing renal artery stenosis. Ann Intern Med 2004; 141:674-82; discussion 682

22. Cooper CJ, Murphy TP, Cutlip DE, et al; CORAL Investigators. Stenting and medical therapy for atherosclerotic renal-artery stenosis. N Engl J Med 2014; 370:13-22.

23. Tan A, Cheung YY, Yin J, et al. Prevalence of sleep-disordered breathing in a multiethnic Asian population in Singapore: A community-based study. Respirology 2016 Feb 29.

24. Young T, Skatrud J, Peppard PE. Risk factors for obstructive sleep apnea in adults. JAMA 2004; 291:2013-6.

25. Peppard PE, Young T, Palta M, Skatrud J. Prospective study of the association between sleep-disordered breathing and hypertension. $\mathrm{N} \mathrm{Engl}$ I Med 2000; 342:1378-84

26. Young T, Peppard P, Palta M, et al. Population-based study of sleepdisordered breathing as a risk factor for hypertension. Arch Intern Med 1997; 157:1746-52.

27. Lavie $P$, Herer $P$, Hoffstein V. Obstructive sleep apnoea syndrome as a risk factor for hypertension: population study. BMJ 2000; 320:479-82

28. Logan AG, Perlikowski SM, Mente A, et al. High prevalence of unrecognized sleep apnoea in drug-resistant hypertension. J Hypertens $2001 ; 19: 2271-7$.

29. White J, Cates C, Wright J. Continuous positive airways pressure for obstructive sleep apnoea. Cochrane Database Syst Rev 2002; (2):CD001106.

30. Durán-Cantolla J, Aizpuru F, Martínez-Null C, Barbé-Illa F. Obstructive sleep apnea/hypopnea and systemic hypertension. Sleep Med Rev 2009; 13:323-31.

31. Turnbull F; Blood Pressure Lowering Treatment Trialists' Collaboration. Effects of different blood-pressure-lowering regimens on major cardiovascular events: results of prospectively-designed overviews of randomised trials. Lancet 2003; 362:1527-35.

32. Martínez-García MA, Capote F, Campos-Rodríguez F, et al; Spanish Sleep Network. Effect of CPAP on blood pressure in patients with obstructive sleep apnea and resistant hypertension: the HIPARCO randomized clinical trial. JAMA 2013; 310:2407-15.

33. Baguet JP, Legallicier B, Auquier P, Robitail S. Updated meta-analytical approach to the efficacy of antihypertensive drugs in reducing blood pressure. Clin Drug Investig 2007; 27:735-53. 


\section{SINGAPORE MEDICAL COUNCIL CATEGORY 3B CME PROGRAMME} (Code SMJ 201605A)

1. Hypertension is the most common chronic diagnosis in all primary care clinics in Singapore.

2. Secondary hypertension is common in older adults, including primary aldosteronism, renal parenchymal disease, renal artery stenosis and obstructive sleep apnoea (OSA).

3. It is important to diagnose and treat secondary causes of hypertension, as it can lead to cardiovascular and renal complications as well as increased healthcare costs if left undiagnosed.

4. Coarctation of the aorta and glomerulonephritis are important causes to consider in a young hypertensive patient $(<30$ years of age).

5. Secondary causes of hypertension are uncommon in older patients $>50$ years of age and should not be considered for diagnosis.

6. The first step in treating a patient with uncontrolled hypertension is the addition of another antihypertensive medication.

7. Primary aldosteronism is rare and should only be considered in young patients with hypertension and hypokalaemia.

8. Primary aldosteronism presents in older adults and is asymptomatic; patients are often normokalaemic.

9. Serum aldosterone and renin levels of patients with severe or resistant hypertension should be screened for the diagnosis of primary aldosteronism.

10. It is paramount that only certain antihypertensive medications should be used prior to checking aldosterone and renin levels.

11. Primary aldosteronism is a treatable condition, and treatment can lead to improved blood pressure control (and potential cure) and reversal of end-organ complications.

12. Renal parenchymal disease and renal artery stenosis are common in hypertensive adults and a baseline serum creatinine test should be ordered.

13. It is not necessary to monitor serum creatinine levels in patients initiated on an angiotensin-converting enzyme inhibitor.

14. A patient with a renal bruit is unlikely to have renal artery stenosis and Doppler ultrasonography of the renal arteries is not recommended.

15. Discrepant kidney sizes and recurrent flash pulmonary oedema should alert the physician to the possibility of renal artery stenosis.

16. All patients with renal artery stenosis require percutaneous revascularisation.

17. Obstructive sleep apnoea only occurs in obese patients.

18. Obstructive sleep apnoea is common and the diagnosis should be considered in patients with excessive daytime sleepiness, nocturnal gasping or choking events, snoring, and unrefreshing sleep.

19. Male gender, obesity and middle age are identified risk factors for OSA.

20. Once the patient's OSA has been treated, hypertension is often cured and antihypertensive medications are no longer required. 